\title{
Usefulness of the Forrest Classification to Predict Artificial Ulcer Rebleeding during Second-Look Endoscopy after Endoscopic Submucosal Dissection
}

\author{
Duk Su Kim, Yunho Jung, Ho Sung Rhee, Su Jin Lee, Yeong Geol Jo, Jong Hwa Kim, Jae Man Park, II-Kwun Chung, \\ Young Sin Cho, Tae Hoon Lee, Sang-Heum Park and Sun-Joo Kim \\ Division of Gastroenterology, Department of Internal Medicine, Soonchunhyang University College of Medicine, Cheonan, Korea
}

Background/Aims: Delayed post-endoscopic submucosal dissection (ESD) bleeding (DPEB) is difficult to predict and there is controversy regarding the usefulness of prophylactic hemostasis during second-look endoscopy. This study evaluated the risk factors related to DPEB, the relationship between clinical outcomes and the Forrest classification, and the results of prophylactic hemostasis during second-look endoscopy.

Methods: Second-look endoscopy was performed on the day after ESD to check for recent hemorrhage or potential bleeding and the presence of artificial ulcers in all patients.

Results: DPEB occurred in 42 of 581 patients (7.2\%). Multivariate analysis determined that a specimen size $\geq 40 \mathrm{~mm}$ (odds ratio [OR], $3.03 ; p=0.003$ ), and a high-risk Forrest classification (Forrest Ib+IIa+IIb; OR, 6.88; $p<0.001$ ) were risk factors for DPEB. DPEB was significantly more likely in patients classified with Forrest Ib (OR, 24.35; $p<0.001)$, IIa (OR, 12.91; $p<0.001)$, or IIb (OR, 8.31; $p<0.001)$ ulcers compared with Forrest III ulcers. There was no statistically significant difference between the prophylactic hemostasis and nonhemostasis groups (Forrest Ib, $p=0.938$; IIa, $p=0.438$; IIb, $p=0.397$; IIc, $p=0.773$ ) during second-look endoscopy.

Conclusions: The Forrest classification of artificial gastric ulcers during second-look endoscopy seems to be a useful tool for predicting delayed bleeding. However, routine prophylactic hemostasis during second-look endoscopy seemed to not be useful for preventing DPEB. Clin Endosc 2016;49:273-281

Key Words: Stomach neoplasms; Hemorrhage; Hemostasis, endoscopic

\section{INTRODUCTION}

Endoscopic submucosal dissection (ESD) is an accepted treatment for gastric adenoma and early gastric cancer (EGC) with results comparable to those after surgery in selected cases. $^{1,2}$ ESD has several advantages over conventional endo-

Received: June 24, 2015 Revised: December 1, 2015

Accepted: December 21, 2015

Correspondence: Il-Kwun Chung

Division of Gastroenterology, Department of Internal Medicine, Soonchunhyang University College of Medicine, 31 Suncheonhyang 6-gil, Dongnam-gu, Cheonan 31151, Korea

Tel: +82-41-570-3741, Fax: +82-41-574-5762, E-mail: euschung@schmc.ac.kr

* Duk Su Kim and Yunho Jung contributed equally to this work as first authors.

(c) This is an Open Access article distributed under the terms of the Creative Commons Attribution Non-Commercial License (http://creativecommons.org/ licenses/by-nc/3.0) which permits unrestricted non-commercial use, distribution, and reproduction in any medium, provided the original work is properly cited. scopic mucosal resection, including a low local recurrence rate and high rates of en bloc and complete resection. Although ESD is an acceptable treatment modality, complications such as perforation and bleeding are serious and can be fatal. Delayed post-ESD bleeding (DPEB) is a major complication that occurs in approximately $2 \%$ to $13.5 \%$ of patients. ${ }^{3-8}$ In cases of massive bleeding, blood transfusion and hospitalization are often required. For that reason, various endoscopic methods, such as argon plasma coagulation (APC) and hemoclips, have been used to prevent DPEB from visible exposed vessels in artificial ulcers. ${ }^{9}$ DPEB can also be prevented by administering a proton pump inhibitor. ${ }^{10,11}$

A recent study reported that second-look endoscopy may be useful for preventing DPEB; ${ }^{5}$ however, other studies demonstrated that routine second-look endoscopy was excessive or unnecessary because the incidence and clinical 
outcomes of DPEB did not improve., ${ }^{4,-8}$ The pathophysiologic mechanism of peptic ulcers and artificial ulcers after ESD is different. ${ }^{12,13}$ Thus, there is controversy regarding routine second-look endoscopy after performing ESD and there is no established treatment strategy for preventing DPEB.

In peptic ulcer bleeding, the Forrest classification has proven useful in the prediction of rebleeding risk and mortality. ${ }^{14-16}$ However, there is no clinical data about the relationship between clinical outcome and Forrest classification of post-ESD ulcers during second-look endoscopy. The aim of this study is to evaluate the usefulness of the Forrest classification of artificial gastric ulcers during second-look endoscopy for predicting clinical outcomes.

\section{MATERIALS AND METHODS}

We retrospectively reviewed 605 patients diagnosed as having gastric epithelial neoplasia who were consecutively treated using ESD at Soonchunhyang University College of Medicine (Cheonan, Korea) from March 2008 to January 2013. This study was approved by the Institutional Review Board of Soonchunhyang University Cheonan Hospital. ESD was principally indicated for adenomas and possible node-negative EGC based on the criteria developed by Gotoda et al. ${ }^{17}$ We excluded two patients with perforated lesions, three with post-operative bleeding within 24 hours after ESD, and 19 who did not undergo second-look endoscopy. All patients

605 Lesion treated by ESD from March 2008 to January 2013

Excluded

$\rightarrow 2$ Lesions of perforation

3 Lesions of post-ESD bleeding within 24 hours

19 Lesions of follow-up loss

581 Lesions

for the analysis of delayed post-ESD bleeding after SLE

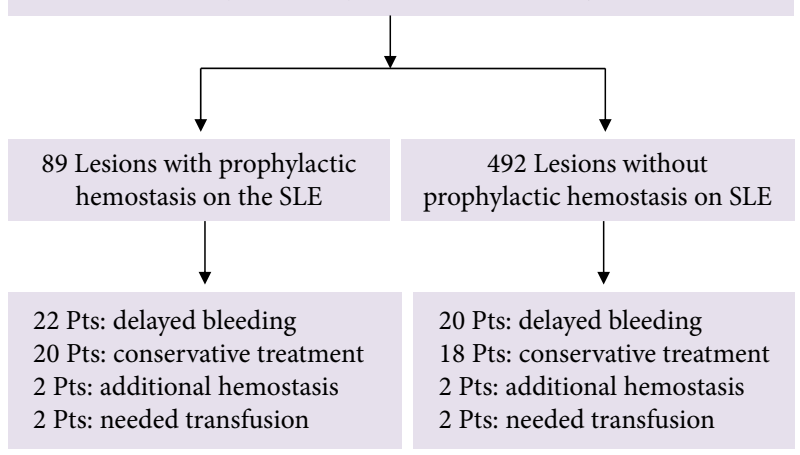

Fig. 1. Flowchart showing the inclusion in the analysis of delayed post-endoscopic submucosal dissection (ESD) bleeding after the second-look endoscopy (SLE). Pt, point. provided informed written consent before undergoing treatment. A flow chart outlining patient enrollment is shown in Fig. 1.

\section{Definition of terms}

Early post-ESD bleeding was defined as bleeding diagnosed within 24 hours after ESD. DPEB was defined as bleeding diagnosed after 24 hours following ESD. ${ }^{7}$ Bleeding was defined as hematemesis, massive melena, or hematochezia after ESD; a $2.0 \mathrm{~g} / \mathrm{dL}$ decrease in hemoglobin after ESD; or bleeding that required a blood transfusion for hypotension, hematochezia, or hematemesis.

\section{Preoperative treatment}

All patients taking antithrombotic drugs, including antiplatelet and anticoagulant drugs, were asked to stop the medication 1 week prior to ESD and after treatment if they were considered to be at low risk for thromboembolism. For high-risk patients, intravenous heparin was administered until 6 hours prior to ESD. In all patients, an $80 \mathrm{mg}$ intravenous loading dose bolus of pantoprazole was administered over 30 minutes an hour prior to ESD and was continuously infused at $8 \mathrm{mg} / \mathrm{hr}$ for 24 hours.

\section{ESD procedure}

ESD was performed with patients under conscious sedation using midazolam, pethidine, or propofol using an EVIS LUCERA SPECTRUM system (Olympus, Tokyo, Japan), with a GIF-H260, or a GIF-H260Z high-resolution upper gastrointestinal endoscope (Olympus). We also performed magnifying endoscopy with narrow-band imaging and acetic acid-indigo carmine chromoendoscopy to determine the lateral extent of the gastric tumor before ESD. Circumferential markings were created approximately $3 \mathrm{~mm}$ outside the border of the lesion by using APC. We injected a $0.025 \mathrm{mg} / \mathrm{mL}$ epinephrine solution into the submucosal layer. Circumferential cutting was performed with a standard needle-knife or insulation-tipped diathermic knife (KD-610L; Olympus) or flex knife (KD630L; Olympus) outside the indicated area. After completing circumferential cutting, the lesion was dissected using an insulation-tipped diathermic knife or flex knife. During ESD, bleeding was coagulated using APC or hemostatic clips. After completion of ESD, we coagulated all non-bleeding visible vessels in the artificial ulcer bed.

\section{Post-ESD treatment and second-look endoscopy}

After 24 hours, $40 \mathrm{mg}$ /day oral pantoprazole or an equivalent proton pump inhibitor was administered for 4 weeks. Second-look endoscopy was performed on the day after ESD to check for recent hemorrhage or potential bleeding and the 
presence of artificial ulcers in all patients. These ulcers were categorized into six patterns according to the Forrest classification. ${ }^{14}$ The Forrest classification differentiates ulcers with a spurting hemorrhage (Forrest Ia), an oozing hemorrhage (Forrest Ib), with a visible vessel (Forrest IIa), an adherent clot (Forrest IIb), hematin on the ulcer base (Forrest IIc), and a clean ulcer base (Forrest III). We also determined the bleeding rates after second-look endoscopy based on the type of artificial ulcer. When Forrest Ib, IIa, IIb, and IIc ulcers were observed, the operator made a subjective decision as to whether to perform prophylactic hemostasis. Prophylactic hemostasis was not performed for Forrest III ulcers. If there was no sign of bleeding, patients were permitted clear water and a liquid diet. Oral antithrombotic treatment was restarted when hemostasis was confirmed by second-look endoscopy. If there was an oozing hemorrhage classified Forrest Ib ulcer or severe abdominal pain, patients were allowed to delay initiation of a liquid diet for 1 day or until pain relief was achieved. A complete blood count was routinely performed immediately following and 1 day after ESD. Patients without any further events were discharged 1 week after ESD. All of the enrolled patients visited the hospital approximately 7 days after discharge, even the patients who had no adverse events related to the ESD procedure. All patients were asked to visit a hospital if they experienced any signs of bleeding, such as melena or hematemesis, and to call our hospital if they visited other hospitals due to bleeding. Patients revisited a hospital approximately 10 and 30 days after discharge and hemoglobin levels and signs of bleeding were routinely checked.

\section{Data analysis}

We reviewed the clinical records, endoscopic findings, and histological reports for all patients. The following variables were analyzed as factors possibly influencing DPEB: (1) patient-related factors such as age, sex, comorbidities (hypertension, diabetes mellitus, cardiovascular disease, liver cirrhosis, and hemodialysis), and daily use of anticoagulants and/or antiplatelet drugs; (2) tumor-related factors such as location (upper third, middle third, or lower third), circumference

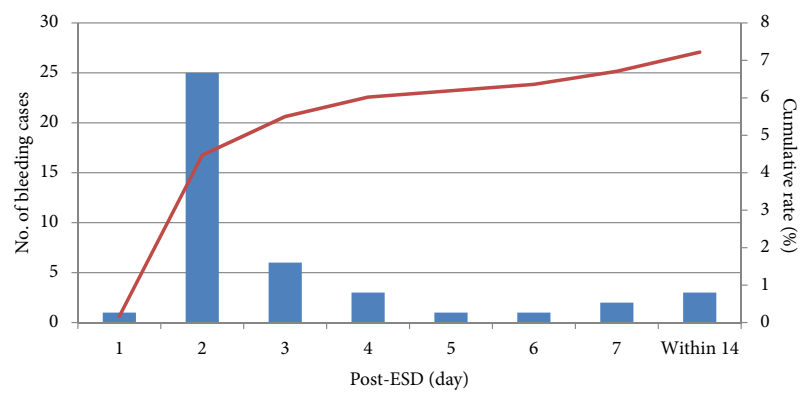

Fig. 2. Number of delayed post-endoscopic submucosal dissection (ESD) bleeding cases and cumulative rate. (anterior wall, posterior wall, lesser curve, or greater curve), gross type (elevated, flat, or depressed), tumor size (the greatest diameter of tumor actually measured), pathologic type (differentiated, well, or moderately differentiated adenocarcinoma/papillary adenocarcinoma; undifferentiated, poorly differentiated adenocarcinoma/signet-ring cell carcinoma; others, adenoma/gastritis), tumor depth (mucosal tumor or submucosal invasive tumor); (3) treatment-related factors such as size of tumor and resected specimen (the greatest diameter of resected tumor actually measured), resection style (en bloc or piecemeal), operation time, artificial gastric ulcer type at second-look endoscopy (the Forrest classification), and hemostasis at second-look endoscopy. DPEB rates of all Forrest type artificial gastric ulcers were compared to those of Forrest III type artificial gastric ulcers and subgroup analyses were performed to assess any association between DPEB and the Forrest classification according to prophylactic hemostasis after ESD.

\section{Statistical analysis}

Statistical analysis was performed using SPSS version 14.0 (SPSS Inc., Chicago, IL, USA). Univariate analysis was performed using Student $t$-test for age, tumor size, and procedure time, and the chi-square test or Fisher exact test for sex, comorbidities, the use of antiplatelet drugs and/or anticoagulants, tumor location and appearance, pathological features, resection style, Forrest classification of artificial ulcers, and with or without hemostasis at second-look endoscopy. A $p<0.05$ was considered to indicate statistical significance. If there was more than one predictor with a significant difference by univariate analysis, multivariate analysis was performed using a logistic regression model.

\section{RESULTS}

ESD was performed in 605 patients, and 581 patients were included in the final evaluation. DPEB occurred in 42 of the 581 patients (Fig. 1). All of the DPEB occurred within 14 days and more than half of the DPEB occurred within 3 days of ESD (Fig. 2). The cumulative rate of DPEB was 7.2\% (Fig. 2). At second-look endoscopy, Forrest Ib ulcers were found in 48 patients (8.2\%). There were 47 Forrest IIa (8.0\%), 80 Forrest IIb (13.7\%), 107 Forrest IIc (19.6\%), and 292 Forrest III (50.2\%) lesions in our study (Table 1).

\section{Risk factors for DPEB}

Univariate analysis showed that a specimen $\geq 40 \mathrm{~mm}$ $(p<0.001)$ and a high-risk Forrest classification of post-ESD ulcers (Forrest $\mathrm{Ib}+\mathrm{IIa}+\mathrm{IIb}, 78.5 \%$ vs. $26.3 \%$, $p<0.001$ ) were 
Table 1. Univariate Analysis of Risk Factor for Delayed Post-Endoscopic Submucosal Dissection Bleeding

\begin{tabular}{|c|c|c|c|}
\hline Variable & Bleeding $(n=42)$ & No bleeding $(n=539)$ & $p$-value \\
\hline \multicolumn{4}{|l|}{ Patient-related } \\
\hline Age & $62.2 \pm 11.6$ & $64.6 \pm 10.3$ & 0.154 \\
\hline Male:Female & $33: 9$ & $375: 164$ & 0.182 \\
\hline \multicolumn{4}{|l|}{ Comorbidities } \\
\hline Hypertension & $10(23.8)$ & $122(22.6)$ & 0.849 \\
\hline Diabetes mellitus & $8(19.0)$ & $67(12.4)$ & 0.218 \\
\hline Cardiovascular disease & $3(7.7)$ & $36(6.7)$ & 0.755 \\
\hline Liver cirrhosis & $1(2.4)$ & $6(1.1)$ & 0.410 \\
\hline Hemodialysis & $1(2.4)$ & $3(0.6)$ & 0.260 \\
\hline \multicolumn{4}{|l|}{ Use of drug } \\
\hline Anticoagulants/platelets (used/not used) & $7(16.7)$ & $58(10.8)$ & 0.304 \\
\hline \multicolumn{4}{|l|}{ Lesion-related } \\
\hline Upper/middle/lower & $1 / 7 / 34$ & $25 / 58 / 456$ & 0.423 \\
\hline LC/GC/AW/PW & $17 / 5 / 11 / 9$ & $247 / 105 / 99 / 88$ & 0.349 \\
\hline Elevated/flat/depressed & $12 / 23 / 7$ & $156 / 300 / 83$ & 0.976 \\
\hline \multicolumn{4}{|l|}{ Specimen size } \\
\hline Mean $\pm S D, m m$ & $36.6 \pm 11.7$ & $30.65 \pm 10.7$ & 0.001 \\
\hline$<40 \mathrm{~mm} / \geq 40 \mathrm{~mm}$ & $24 / 18$ & $450 / 89$ & $<0.001$ \\
\hline Differentiated/undifferentiated/others ${ }^{\mathrm{a})}$ & $23 / 4 / 15$ & $266 / 24 / 249$ & 0.197 \\
\hline \multicolumn{4}{|l|}{ Depth of invasion } \\
\hline $\mathrm{M} / \mathrm{SM}$ & $36 / 6$ & $488 / 51$ & 0.286 \\
\hline $\mathrm{M}+\mathrm{SM}$ minute/SM massive & $38 / 4$ & $505 / 34$ & 0.344 \\
\hline \multicolumn{4}{|l|}{ Resection } \\
\hline En bloc/piecemeal & $41 / 1$ & $524 / 15$ & 0.999 \\
\hline Curative/non-curative & $40 / 2$ & $483 / 56$ & 0.418 \\
\hline Operation time, min & $53.2 \pm 27.7$ & $55.9 \pm 14.5$ & 0.548 \\
\hline Artificial gastric ulcer at second-look endoscopy & & & $<0.001$ \\
\hline Forrest Ib & 15 & 33 & \\
\hline Forrest IIa & 7 & 40 & \\
\hline Forrest IIb & 11 & 69 & \\
\hline Forrest IIc & 4 & 110 & \\
\hline Forrest III & 5 & 287 & \\
\hline Forrest Ib+IIa+IIb/IIc+III & $33 / 9$ & $142 / 397$ & $<0.001$ \\
\hline
\end{tabular}

Values are presented as mean \pm SD or number (\%).

LC, lesser curvature; GC, greater curvature; AW, anterior wall; PW, posterior wall; $\mathrm{M}$, tumor confined to the mucosa; SM minute, tumor invading the submucosa $<500 \mathrm{~mm}$; SM massive, tumor invading the submucosa $\geq 500 \mathrm{~mm}$.

${ }^{a}$ Differentiated (well or moderately differentiated adenocarcinoma/papillary adenocarcinoma), undifferentiated (signet-ring cell carcino$\mathrm{ma}$ /poorly differentiated adenocarcinoma), others (adenoma/gastritis).

significant risk factors for DPEB (Table 1). Subgroup analyses were performed to identify risk factors for higher re-bleeding risk for Forrest Ib and IIa lesions. In this analysis, a specimen $\geq 40 \mathrm{~mm}$ was the only significant risk factor for DPEB (odds ratio $[\mathrm{OR}], 2.74 ; 95 \%$ confidence interval $[\mathrm{CI}], 1.01$ to 7.45 ; $p=0.043$ ) (Table 2). Multivariate analysis determined that a specimen $\geq 40 \mathrm{~mm}$ (OR, 3.03; 95\% CI, 1.47 to $6.22 ; p=0.003)$, and high-risk Forrest classification (Forrest Ib+IIa+IIb: OR, 6.88; 95\% CI, 2.81 to 16.88 ; $p<0.001)$ were risk factors for DPEB (Table 3). 
Table 2. Result of Subgroup Analysis: Univariate Analysis of Risk Factor for Delayed Post-Endoscopic Submucosal Dissection Bleeding in Forrest Ib, Ila

\begin{tabular}{|c|c|c|c|}
\hline Variable & Bleeding $(n=22)$ & No bleeding $(n=73)$ & $p$-value \\
\hline \multicolumn{4}{|l|}{ Patient-related } \\
\hline Age & $63.2 \pm 9.4$ & $64.1 \pm 10.7$ & 0.739 \\
\hline Male:Female & $17: 5$ & $47: 26$ & 0.258 \\
\hline \multicolumn{4}{|l|}{ Comorbidities } \\
\hline Hypertension & $7(31.8)$ & $14(19.2)$ & 0.210 \\
\hline Diabetes mellitus & $4(18.2)$ & $10(13.7)$ & 0.732 \\
\hline Cardiovascular disease & $2(9.1)$ & $4(5.5)$ & 0.620 \\
\hline Liver cirrhosis & $1(4.5)$ & $1(1.4)$ & 0.411 \\
\hline Hemodialysis & $1(4.5)$ & $1(1.4)$ & 0.411 \\
\hline \multicolumn{4}{|l|}{ Use of drug } \\
\hline Anticoagulants/platelets (used/not used) & $3(13.6)$ & $7(9.6)$ & 0.693 \\
\hline \multicolumn{4}{|l|}{ Lesion-related } \\
\hline Upper/middle/lower & $0 / 3 / 19$ & $2 / 5 / 66$ & 0.459 \\
\hline LC/GC/AW/PW & $9 / 1 / 7 / 5$ & $42 / 8 / 14 / 9$ & 0.254 \\
\hline Elevated/flat/depressed & $6 / 11 / 5$ & $17 / 51 / 5$ & 0.075 \\
\hline \multicolumn{4}{|l|}{ Specimen size } \\
\hline Mean $\pm S D, m m$ & $38.0 \pm 10.7$ & $31.7 \pm 10.1$ & 0.014 \\
\hline$<40 \mathrm{~mm} / \geq 40 \mathrm{~mm}$ & $10 / 12$ & $56 / 17$ & 0.043 \\
\hline Differentiated/undifferentiated/others ${ }^{\text {a) }}$ & $14 / 2 / 6$ & $43 / 1 / 29$ & 0.138 \\
\hline \multicolumn{4}{|l|}{ Depth of invasion } \\
\hline $\mathrm{M} / \mathrm{SM}$ & $19 / 3$ & $70 / 3$ & 0.107 \\
\hline \multicolumn{4}{|l|}{ Resection } \\
\hline En bloc/piecemeal & $21 / 1$ & $70 / 3$ & 0.929 \\
\hline Curative/non-curative & $20 / 2$ & $68 / 5$ & 0.661 \\
\hline Operation time, $\min$ & $53.3 \pm 14.9$ & $56.5 \pm 15.0$ & 0.385 \\
\hline
\end{tabular}

Values are presented as mean \pm SD or number (\%).

LC, lesser curvature; GC, greater curvature; AW, anterior wall; PW, posterior wall; $\mathrm{M}$, tumor confined to the mucosa; SM, tumor confined to the submucosa.

${ }^{a}$ Differentiated (well or moderately differentiated adenocarcinoma/papillary adenocarcinoma), undifferentiated (signet-ring cell carcino$\mathrm{ma}$ /poorly differentiated adenocarcinoma), others (adenoma/gastritis).

Table 3. Multivariate Analysis of Risk Factor for Delayed Post-Endoscopic Submucosal Dissection Bleeding

\begin{tabular}{lccc}
\hline & OR & 95\% CI & p-value \\
\hline High risk artificial ulcer (Forrest Ib+IIa+IIb) & 6.88 & $2.805-16.8$ & $<0.001$ \\
Specimen size $(\geq 40 \mathrm{~mm})$ & 3.02 & $1.471-6.22$ & 0.003 \\
\hline
\end{tabular}

OR, odds ratio; $\mathrm{CI}$, confidence interval.

The relationship between DPEB and Forrest classification

DPEB rates of Forrest Ib, IIa, and IIb ulcers were 31.3\%, $14.9 \%$, and $13.8 \%$, respectively. Forrest IIc (3.5\%) and III (1.7\%) ulcers had relatively lower rates of DPEB. DPEB was significantly increased in Forrest Ib (OR, 24.35; 95\% CI, 8.24 to $71.9 ; p<0.001)$, Forrest IIa (OR, 12.91; $95 \%$ CI, 4.12 to 40.47 ; $p<0.001$ ), and Forrest IIb (OR, 8.31; 95\% CI, 2.75 to 25.12; $p<0.001)$ ulcers compared with Forrest III ulcers. However, there was no significant differences in the DPEB rate between Forrest III and Forrest IIc ulcers ( $p=0.279$ ) (Table 4, Fig. 3).

\section{Results of prophylactic hemostasis during sec- ond-look endoscopy}

In Forrest Ib ulcers, DPEB occurred in eight of 26 patients after the prophylactic hemostatic procedure (30.8\%; OR, 25.51; 


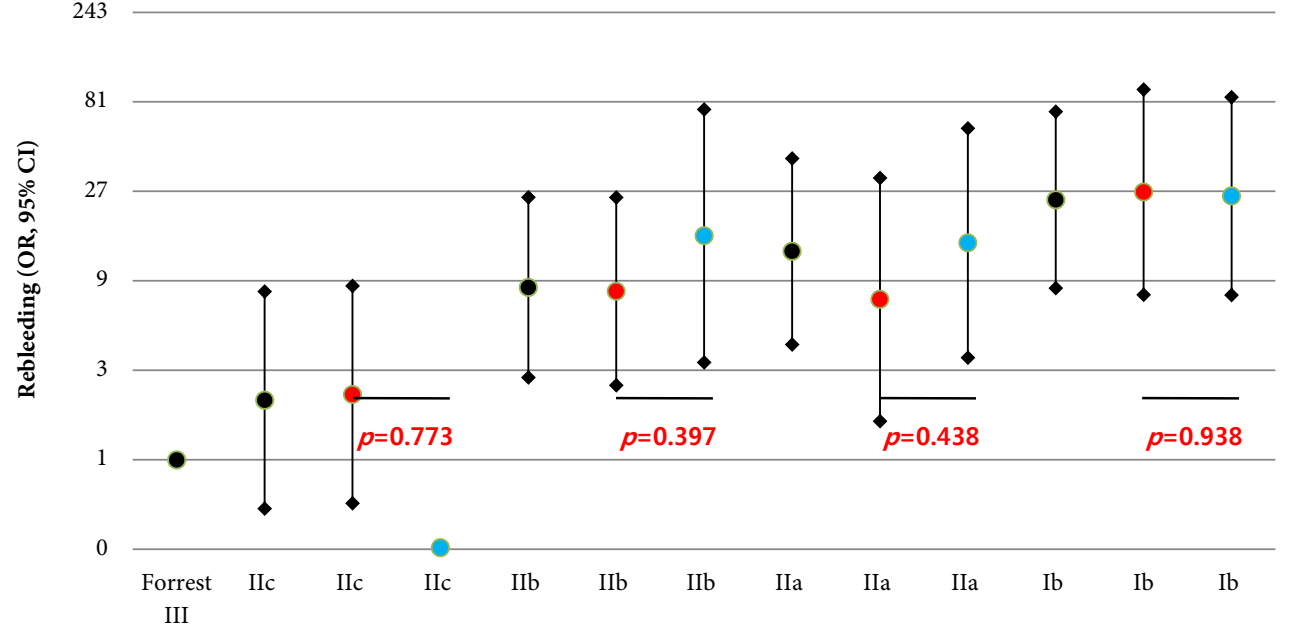

Fig. 3. Association between Forrest classification and delayed post-endoscopic submucosal dissection (ESD) bleeding (black stacks). Result of subgroup analysis, association between Forrest classification, and delayed post-ESD bleeding in artificial gastric ulcers with (blue stacks) and without prophylactic hemostasis (red stacks). OR, odds ratio; $\mathrm{Cl}$, confidence interval.

Table 4. Association between Delayed Post-Endoscopic Submucosal Dissection Bleeding and Forrest Classification

\begin{tabular}{lccccc}
\hline Forrest type & Number & Bleeding, no. (\%) & OR & 95\% CI & p-value \\
\hline Forrest Ib & 48 & $15(31.3)$ & 24.35 & $8.24-71.9$ & $<0.001$ \\
Forrest IIa & 47 & $7(14.9)$ & 12.91 & $4.12-40.5$ & $<0.001$ \\
Forrest IIb & 80 & $11(13.8)$ & 8.31 & $2.75-25.1$ & $<0.001$ \\
Forrest IIc & 114 & $4(3.5)$ & 2.08 & $0.55-7.91$ & 0.279 \\
Forrest III & 292 & $5(1.7)$ & 1 & 1 & -
\end{tabular}

Delayed post-endoscopic submucosal dissection bleeding risk of all Forrest type artificial gastric ulcers were compared with artificial gastric ulcers Forrest III.

$\mathrm{OR}$, odds ratio; $\mathrm{CI}$, confidence interval.

95\% CI, 7.57 to $85.94 ; p<0.001)$ and seven of 22 patients after observation (31.8\%; OR, 26.78; 95\% CI, 7.60 to 94.39 ; $p<0.010$ ). In Forrest IIa ulcers, DPEB occurred in four of 20 patients after the prophylactic hemostatic procedure (20.0\%; OR, 14.35; 95\% CI, 3.51 to $58.65 ; p<0.001)$ and three of 27 patients after observation (11.1\%; OR, 7.17; 95\% CI, 1.61 to 31.05 ; $p=0.010$ ). In Forrest IIb ulcers, DPEB occurred in three of 14 patients after the prophylactic hemostatic procedure $(21.4 \%$; OR, 15.65 ; $95 \%$ CI, 3.31 to 73.96 ; $p=0.001$ ) and eight of 66 after observation (12.1\%; OR, 7.91; 95\% CI, 2.50 to 25.06; $p<0.001)$. In Forrest III ulcers, DPEB occurred in five of 292 patients after observation (1.7\%) (Table 5).

There was no significant difference in DPEB rates between the prophylactic hemostasis and non-hemostasis groups (Forrest Ib, $p=0.938$; Forrest IIa, $p=0.438$; Forrest IIb, $p=0.397$; Forrest IIc, $p=0.773$ ). In Forrest IIa and IIb ulcers, DPEB occurred more frequently in the prophylactic hemostasis group than the non-hemostasis group; however, these differences were not statistically significant (Fig. 3).

Most cases of DPEB were managed with conservative treatment without performing additional endoscopic hemostasis or surgical intervention. Only four patients required blood transfusion and an additional endoscopic hemostatic procedure. There was no significant difference in the requirement for transfusion between the prophylactic hemostasis and non-hemostasis group (2/89 [2.2\%] vs. $2 / 492$ [0.4\%], $p=0.113)$

(Fig. 1).

\section{DISCUSSION}

Previous studies reported that the size of the resected tumor was the only significant risk factor for post-ESD bleeding. ${ }^{18,19}$ However, there is little clinical data describing the relationship between DPEB and Forrest classification of artificial gastric ulcers during second-look endoscopy. In our study, multivariate analysis determined that a specimen $\geq 40 \mathrm{~mm}$ was a significant risk factor for DPEB (OR, 3.03; 95\% CI, 1.47 to 6.22; $p=0.003$ ). Ulcers with high-risk Forrest classifications such as $\mathrm{Ib}$, IIa, and IIb were another significant risk factor for DPEB (OR, 6.88; 95\% CI, 2.81 to 16.88; $p<0.001$ ). Subgroup analyses were performed to identify risk factors for higher re-bleeding risk lesions classified as Forrest Ib and IIa. In this analysis, a specimen $\geq 40 \mathrm{~mm}$ was the only significant risk factor for 
Table 5. Result of Subgroup Analysis: Association between Delayed Post-Endoscopic Submucosal Dissection Bleeding (ESD) and Forrest Classification according to Prophylactic Hemostasis after ESD

\begin{tabular}{|c|c|c|c|c|c|}
\hline & Number & Bleeding, $n(\%)$ & OR & $95 \% \mathrm{CI}$ & $p$-value \\
\hline \multicolumn{6}{|c|}{ Prophylactic hemostasis after ESD } \\
\hline Forrest Ib & 48 & & & & \\
\hline Yes & 26 & $8(30.8)$ & 25.51 & $7.57-85.94$ & $<0.001$ \\
\hline No & 22 & $7(31.8)$ & 26.78 & $7.60-94.39$ & $<0.001$ \\
\hline Forrest IIa & 47 & & & & \\
\hline Yes & 20 & $4(20.0)$ & 14.35 & $3.51-58.7$ & $<0.001$ \\
\hline No & 27 & $3(11.1)$ & 7.17 & $1.61-31.5$ & 0.010 \\
\hline Forrest IIb & 80 & & & & \\
\hline Yes & 14 & $3(21.4)$ & 15.65 & $3.31-74.0$ & $<0.001$ \\
\hline No & 66 & $8(12.1)$ & 7.91 & $2.50-25.1$ & $<0.001$ \\
\hline Forrest IIc & 114 & & & & \\
\hline Yes & 7 & 0 & 0 & 0 & 0.999 \\
\hline No & 107 & $4(3.5)$ & 2.22 & $0.58-8.46$ & 0.239 \\
\hline Forrest III & 292 & & & & \\
\hline Yes & 0 & 0 & - & - & - \\
\hline No & 292 & $5(1.7)$ & 1 & 1 & - \\
\hline
\end{tabular}

Delayed post-ESD bleeding risk of all Forrest type artificial gastric ulcers were compared with artificial gastric ulcers Forrest III.

OR, odds ratio; $\mathrm{CI}$, confidence interval.

\section{DPEB (OR, 2.74; 95\% CI, 1.01 to $7.45 ; p=0.043$ ).}

The main purpose of our study was to evaluation the usefulness of the Forrest classification of artificial gastric ulcers during second-look endoscopy for predicting DPEB. All three Forrest Ia patients were diagnosed with emergency bleeding within 24 hours of performing ESD. Thus, we could not observe the Forrest Ia ulcers during second-look endoscopy. A more detailed analysis determined that DPEB was significantly increased in Forrest Ib (OR, 24.35; 95\% CI, 8.24 to $71.9 ; p<0.001)$, Forrest IIa (OR, 12.91; $95 \%$ CI, 4.12 to 40.47 ; $p<0.001$ ), and Forrest IIb (OR, 8.31; 95\% CI, 2.75 to 25.12; $p<0.001)$ ulcers compared with Forrest III ulcers. There was no significant difference in the DPEB rate between Forrest III and Forrest IIc ulcers (OR, 2.08; 95\% CI, 0.55 to 7.91; $p<0.001$ ). This result showed that the Forrest classification is useful to identify patients who are high risk of DPEB.

Previous studies showed the efficacy of a second-look endoscopy after endoscopic hemostasis to prevent delayed bleeding in bleeding peptic ulcer cases. ${ }^{20-22}$ These studies are the basis for routine performance of second-look endoscopy after gastric ESD at many institutions. A recent retrospective study reported that second-look endoscopy might be useful for preventing post-ESD bleeding, because DPEB occurred less frequently after second-look endoscopy (one case in 432 patients vs. eight cases in 440 patients). ${ }^{5}$ However, other prospective and retrospective controlled trials showed that second-look endoscopy did not affect clinical outcomes or morbidity, including bleeding (second-look group 16.2\% [12/74] vs. non-second-look group $11.1 \%$ [9/81], $p=0.66)^{6}$ and (second-look group 1.0\% [2/194] vs. non-second-look group 2.5\% [9/353], $p=0.343)^{8}$ after ESD. However, controversies remain regarding second-look endoscopy after gastric ESD.

Since recent studies demonstrated that prophylactic hemostasis during a second-look endoscopy did not improved clinical outcomes, we analyzed the relationship between Forrest classification of artificial gastric ulcers and DPEB after prophylactic hemostasis during second-look endoscopy. There was no significant difference between the prophylactic hemostasis and non-hemostasis groups (Forrest Ib, $p=0.938$; Forrest IIa, $p=0.438$; Forrest IIb, $p=0.397$; Forrest IIc, $p=0.773$ ).

There are basic differences between the pathophysiologic mechanisms of peptic ulcers and artificial gastric ulcers after ESD. ${ }^{6,12,13}$ Peptic ulcers are usually created under low $\mathrm{pH}$ conditions and develop following the breakdown of gastric mucosal defense mechanisms due to nonsteroidal anti-inflammatory drug use. These ulcers are found deeper in the submucosa, and inflammation spreads to the ulcer periphery, so peptic ulcers may have the potential to bleed even after the initial hemostasis. A recent meta-analysis of patients with acute peptic ulcer bleeding reported the effectiveness of second-look endoscopy in reducing delayed bleeding (OR, 0.55; 95\% CI, 0.37 to 0.81$){ }^{23}$ Whereas, post-ESD ulcers occur iatrogenically at 
sites where mucosal defense mechanisms are intact. Post-ESD ulcers are created under relatively high $\mathrm{pH}$ conditions due to proton-pump inhibitor pre-medication. Iatrogenic ulcers usually have localized inflammation with a relatively shallow depth. Bleeding and non-bleeding visible vessels are strictly treated by APC or hemostatic clips during ESD. For these reasons, prophylactic hemostasis during second-look endoscopy seems to not have any additional advantage for preventing DPEB. In our study, the incidence of DPEB was not statistically significantly different between the prophylactic hemostasis and non-hemostasis group.

Interestingly, in Forrest IIa and IIb ulcers, DPEB occurred more frequently in the prophylactic hemostasis group than the non-hemostasis group, although these differences were not significant. Moreover, prophylactic hemostasis during second-look endoscopy does not affect the clinical outcomes of DPEB incidence or the requirement for transfusion (2/89 [2.2\%] vs. $2 / 492$ [0.4\%], $p=0.113)$. Mochizuki et al., ${ }^{24}$ a Japanese multicenter prospective randomized controlled trial (the SAFE trial), showed that delayed bleeding in patients who received prophylactic hemostasis during second-look endoscopy occurred more frequently than in patients who did not receive it, although this difference was not statistically significant (3/42 [7.1\%] vs. $2 / 84$ [2.4\%], $p=0.332$ ). The reason why DPEB still occurred in patients who underwent prophylactic hemostasis is unclear. We assumed that air insufflations and the hemostatic procedure could have induced tissue injury. Accordingly, prophylactic hemostatic procedures during second-look endoscopy may have contributed to the exposure of arteries on the base of the artificial ulcer, which in turn contributed to DPEB. We think that hemostasis during the second-look endoscopy is not helpful to prevent delayed bleeding.

Although prophylactic hemostasis during second-look endoscopy had no additional advantage in preventing DPEB, the Forrest classification of post-ESD ulcers during second-look endoscopy can help predict the risk of DPED. We believe that prediction of DPEB with the Forrest classification of postESD ulcers at second-look endoscopy is important, because it can help determine diet, discharge, and prevention plans for delayed bleeding, such as pharmacologic prevention or hemostasis, keeping in mind that prophylactic hemostasis during the second-look endoscopy seemed to not be helpful in preventing DPEB. Prospective and randomized controlled trials should be conducted to evaluate the efficacy of massive pharmacologic treatment and prophylactic hemostasis, including devices.

There were several limitations to our study. This is a retrospective study from a single center. Thus, the selection of prophylactic hemostasis cases might be affected by endoscopists' characteristics and more vulnerable lesions, even though the
Forrest classification is the same. We could not make a true comparison between the groups with or without prophylactic hemostasis. This bias could have resulted in our finding of no effectiveness of prophylactic hemostasis. Multicenter, prospective, randomized controlled trials are necessary to determine the benefit of second-look endoscopy with prophylactic hemostasis.

In conclusion, the Forrest classification of artificial gastric ulcers during second-look endoscopy seems to be a useful tool for predicting delayed bleeding. However, routine prophylactic hemostasis during second-look endoscopy seemed to not be helpful in preventing DPEB.

Conflicts of Interest

The authors have no financial conflicts of interest.

\section{REFERENCES}

1. Min YW, Min BH, Lee JH, Kim JJ. Endoscopic treatment for early gastric cancer. World J Gastroenterol 2014;20:4566-4573.

2. Gotoda T. Endoscopic resection of early gastric cancer. Gastric Cancer 2007;10:1-11.

3. Chung IK, Lee JH, Lee SH, et al. Therapeutic outcomes in 1000 cases of endoscopic submucosal dissection for early gastric neoplasms: Korean ESD Study Group multicenter study. Gastrointest Endosc 2009;69:12281235.

4. Goto O, Fujishiro M, Kodashima S, et al. A second-look endoscopy after endoscopic submucosal dissection for gastric epithelial neoplasm may be unnecessary: a retrospective analysis of postendoscopic submucosal dissection bleeding. Gastrointest Endosc 2010;71:241-248.

5. Kim HH, Park SJ, Park MI, Moon W. Clinical impact of second-look endoscopy after endoscopic submucosal dissection of gastric neoplasms. Gut Liver 2012;6:316-320.

6. Ryu HY, Kim JW, Kim HS, et al. Second-look endoscopy is not associated with better clinical outcomes after gastric endoscopic submucosal dissection: a prospective, randomized, clinical trial analyzed on an as-treated basis. Gastrointest Endosc 2013;78:285-294.

7. Choi CW, Kim HW, Kang DH, et al. Clinical outcomes of second-look endoscopy after gastric endoscopic submucosal dissection: predictive factors with high risks of bleeding. Surg Endosc 2014;28:2213-2220.

8. Kim ER, Kim JH, Kang KJ, et al. Is a second-look endoscopy necessary after endoscopic submucosal dissection for gastric neoplasm? Gut Liver 2015;9:52-58.

9. Takizawa K, Oda I, Gotoda T, et al. Routine coagulation of visible vessels may prevent delayed bleeding after endoscopic submucosal dissection: an analysis of risk factors. Endoscopy 2008;40:179-183.

10. Uedo N, Takeuchi Y, Yamada T, et al. Effect of a proton pump inhibitor or an $\mathrm{H} 2$-receptor antagonist on prevention of bleeding from ulcer after endoscopic submucosal dissection of early gastric cancer: a prospective randomized controlled trial. Am J Gastroenterol 2007;102:1610-1616.

11. Lee SH, Lee CK, Chung IK, et al. Optimal duration of proton pump inhibitor in the treatment of endoscopic submucosal dissection-induced ulcers: a retrospective analysis and prospective validation study. Dig Dis Sci 2012;57:429-434.

12. Goto O, Fujishiro M, Kodashima S, et al. Short-term healing process of artificial ulcers after gastric endoscopic submucosal dissection. Gut Liver 2011;5:293-297.

13. Muraki Y, Enomoto S, Iguchi M, Fujishiro M, Yahagi N, Ichinose M. Management of bleeding and artificial gastric ulcers associated with endoscopic submucosal dissection. World J Gastrointest Endosc 2012;4:1- 
8.

14. Forrest JA, Finlayson ND, Shearman DJ. Endoscopy in gastrointestinal bleeding. Lancet 1974;2:394-397.

15. Rockall TA, Logan RF, Devlin HB, Northfield TC. Risk assessment after acute upper gastrointestinal haemorrhage. Gut 1996;38:316-321.

16. de Groot NL, van Oijen MG, Kessels K, et al. Reassessment of the predictive value of the Forrest classification for peptic ulcer rebleeding and mortality: can classification be simplified? Endoscopy 2014;46:46-52.

17. Gotoda T, Yamamoto H, Soetikno RM. Endoscopic submucosal dissection of early gastric cancer. J Gastroenterol 2006;41:929-942.

18. Mannen K, Tsunada S, Hara M, et al. Risk factors for complications of endoscopic submucosal dissection in gastric tumors: analysis of 478 lesions. J Gastroenterol 2010;45:30-36.

19. Okada K, Yamamoto Y, Kasuga A, et al. Risk factors for delayed bleeding after endoscopic submucosal dissection for gastric neoplasm. Surg Endosc 2011;25:98-107.

20. Villanueva C, Balanzó J, Torras X, Soriano G, Sáinz S, Vilardell F. Value of second-look endoscopy after injection therapy for bleeding peptic ulcer: a prospective and randomized trial. Gastrointest Endosc 1994;40:3439.

21. Saeed ZA, Cole RA, Ramirez FC, Schneider FE, Hepps KS, Graham DY. Endoscopic retreatment after successful initial hemostasis prevents ulcer rebleeding: a prospective randomized trial. Endoscopy 1996;28:288-294.

22. Chiu PW, Lam CY, Lee SW, et al. Effect of scheduled second therapeutic endoscopy on peptic ulcer rebleeding: a prospective randomised trial. Gut 2003;52:1403-1407.

23. El Ouali S, Barkun AN, Wyse J, et al. Is routine second-look endoscopy effective after endoscopic hemostasis in acute peptic ulcer bleeding? A meta-analysis. Gastrointest Endosc 2012;76:283-292.

24. Mochizuki S, Uedo N, Oda I, et al. Scheduled second-look endoscopy is not recommended after endoscopic submucosal dissection for gastric neoplasms (the SAFE trial): a multicentre prospective randomised controlled non-inferiority trial. Gut 2015;64:397-405. 